\title{
Rent-Sharing and Collective Bargaining Coverage - Evidence from Linked Employer-Employee Data
}

\author{
Nicole Guertzgen \\ Centre for European Economic Research, Mannheim*
}

September 2005

\begin{abstract}
Using a linked employer-employee data set, this paper analyses the relationship between firm-profitability and wages. Particular emphasis is given to the question of whether the sensitivity of wages to firm-specific rents varies with collective bargaining coverage. To address this issue, we distinguish sectorspecific wage agreements, firm-specific wage agreements and wage determination without any bargaining coverage. Our findings indicate that individual wages are positively related to firm-specific rents in the non-union sector and under firm-specific contracts. Industry-wide wage contracts, however, seem to suppress firm-level rent-sharing. While pooled OLS estimates yield a positive correlation between wages and quasi-rents under centralised contracts, estimates accounting for unobserved individual and establishment heterogeneity point to a coefficient of zero. Differenced GMM estimates accounting for the endogeneity of our profitability measure even point to a negative relationship under centralised contracts.
\end{abstract}

Keywords: Rent-Sharing, Unions, Linked Employer-Employee Data

JEL Code: J31, J51, C23

\footnotetext{
${ }^{*}$ Centre for European Economic Research, Department of Labour Markets, Human Resources and Social Policy, L 7.1, 68161 Mannheim, Germany, E-Mail: Guertzgen@zew.de. I am grateful to Alfred Garloff and Michael Maier for helpful comments. I am particularly thankful to Holger Alda for help with the data at the Research Data Centre (FDZ) of the Federal Employment Services (BA) at the Institute for Employment Research (IAB), Nuremberg. The institutions mentioned are not responsible for the use of the data in this publication. Financial support from the German Science Foundation (DFG) under the Program "Potentials for more flexibility on heterogeneous labour markets" (Grant-No. PF 331/3-1) is gratefully acknowledged.
} 
Non-technical summary: This paper analyses whether wages in Germany respond to firm-specific profitability conditions. Particular emphasis is given to the question of whether the sensitivity of wages to firm-specific rents varies with collective bargaining coverage. To address this issue, we distinguish sector-specific wage agreements, firm-specific wage agreements and wage determination without any bargaining coverage. Theoretical considerations lead us to expect the sensitivity of wages to firm-specific rents to be larger under firm-specific contracts than in non-covered firms. The same is likely to hold for industry-wide agreements, provided the bargaining parties make use of flexibility provisions, which recently have become a widespread element of central wage agreements. Since direct information on the use of flexibility provisions in firms subject to an industry-wide wage agreement is unavailable, we take our empirical findings as an indirect test of whether the use of such provisions is a quantitatively important phenomenon in Germany.

Using linked employer-employee data from the mining and manufacturing sector, our empirical analysis offers a remarkably consistent picture: Individual wages are positively related to firm-specific quasi-rents, but this appears to be confined to the non-union sector and to firm-specific contracts. Industry-wide wage agreements, in contrast, appear to suppress rent-sharing at the firm level. While pooled OLS estimates yield a positive correlation between wages and quasi-rents under centralised contracts, estimates accounting for unobserved individual and establishment heterogeneity point to a coefficient of zero. Differenced GMM estimates accounting for the endogeneity of our profitability measure even point to a negative relationship between wages and firm-specific profitability under centralised contracts. Although this result is difficult to interpret, it leads us to conclude that the lower responsiveness of wages to firm-specific conditions under centralised contracts is not simply due to a downward-bias caused by the endogeneity of quasi-rents. In examining the impact of collective bargaining coverage on the wage-profit relationship, our findings therefore suggest that centralised wage bargaining suppresses any positive responsiveness of wages to different profitability conditions, and that the use of flexibility provisions in central wage agreements appears to be empirically negligible. Even though firms may pay wages above the going rate and may make use of opting-out clauses, this potential for positive adjustments to local profitability conditions seems to be largely unused. To reconcile this result with the fact that a considerable fraction of firms covered by a collective contract pay wages above the going rate, we conclude from our findings that such wages do not result from differences in profitability conditions, but rather reflect observable and unobservable differences in worker productivity.

As to the importance of worker characteristics, the invariance of wages against firm-specific conditions is found to be largest for low- and medium-skilled blue-collar workers. This is consistent with our hypothesis that the extent of inter-firm wage compression under centralised contracts ought to be particularly pronounced among those workers who are likely to be covered by collective contracts. In non-covered establishments, we find skilled and male workers to benefit to a larger extent from their employers' ability-to-pay than unskilled and female workers, which lends support to efficiency wage and bargaining power considerations. 


\section{Introduction}

A central question in the economics of wage determination is to what extent wage differentials reflect differences in worker characteristics or differences across employers' for identical workers. As regards the latter, firm-specific profitability conditions are widely recognised as a major source of employer-specific wage differentials. The existing literature offers competing explanations for a positive relationship between wages and firms' ability to pay, such as short-run frictions in a competitive labour market, efficiency wage mechanisms and union power. An empirical test of a positive wage-profit correlation is generally seen as an indirect test of the competitive labour market theory, since the latter is difficult to reconcile with a long-run correlation between wages and profits (see e.g., Blanchflower et al. 1996, Hildreth and Oswald 1997).

A large number of studies have attempted to quantify the impact of profitability conditions on wages. Early studies date back to Slichter (1950) who reports a positive correlation between wages and employers' ability to pay using industry data from U.S. manufacturing. Later work on inter-industry wage differentials documents persistent wage differentials across industries that appear to be correlated with industry-profits (Dickens and Katz 1987, Krueger and Summers 1988, Katz and Summers 1989 and Blanchflower et al. 1996). Most of this work controls for systematic worker differences across industries by using individual data which are matched to industry-specific profitability measures. However, in relying on aggregate profit data those studies typically fail to account for a within-industry correlation between firm profits and wages. Studies using firm-level data overcome this problem, but in general do not control for worker quality (e.g., van Reenen 1996, Hildreth and Oswald 1997, Dobbelaere 2004). Given that one is generally interested in the question of whether identical workers obtain higher wages in more profitable firms, an ideal data set would include linked information on both employers and employees. With this information at hand, it would be possible to account for non-random sorting of high quality workers into more profitable firms. Moreover, linked employer-employee data do also allow to control for unobserved worker and firm heterogeneity, as long as they are available in a longitudinal dimension. To date, there are only few studies investigating the wage-profit relationship using matched worker-firm data. Examples include Margolis and Salvanes (2001), Arai (2003), Nekby (2003), Kramarz (2004) as well as Martins (2004).

The primary objective of our paper is to explore the linkages between firm-specific profits and individual wages using German linked employer-employee data. Partic- 
ular attention will be paid to the question as to whether the sensitivity of wages to firm-specific profits depends on collective bargaining coverage. In pursuing the issue of labor market institutions, our paper is related to a second strand of literature, which emphasises the role of the bargaining structure for the magnitude of inter-industry wage differentials. Based on cross-country comparisons, Holmlund and Zetterberg (1991), Edin and Zetterberg (1992) and Kahn (1998) find countries with highly centralised and coordinated bargaining institutions to exhibit substantially lower inter-industry wage variation than countries with relatively decentralised bargaining systems. Our paper differs from this literature, in that we (1) focus on interfirm wage differentials and (2) exploit intra- instead of international variations in the bargaining structure. ${ }^{1}$

The German case provides an instructive example for the co-existence for different bargaining structures. Until the early 1990s, wage determination was dominated by centralised wage bargaining between industry-specific unions and employers' associations. However, in the last decade, there has been a tendency towards decentralisation of wage determination, since firm-specific collective wage agreements as well as wage determination without any bargaining coverage have become more important (Hassel 1999, Ochel 2005). Even within centralised industry agreements, there have been numerous attempts to allow for more (downward) flexibility of wages by introducing opening and hardship clauses. Moreover, since bargained wages in centralised agreements merely represent a lower bound for wages, there is also sufficient room for upward flexibility. Given that recent decentralisation tendencies have introduced - at least formally - the possibility to adjust wages to local conditions at the firm level, a further purpose of the paper is to shed light on the following questions: Do firmspecific contracts and flexibility provisions in centralised industry agreements allow for rent-sharing at the firm level? If yes, does the extent to which wages respond to profits differ from that in firms without any bargaining coverage? Moreover, linked employer-employee data also allow us to address the question as to whether certain groups of workers benefit more from firms' ability-to-pay than others. There are only few previous studies on the relationship between wages and profits in Germany and, to our knowledge, there is no study that uses matched worker-firm data. Hübler and König (1998) and Klodt (2000) use data from the 'Hannover Establishment Panel'. They report a significant positive impact of profits on average firm wages, but do not allow the effect to vary with bargaining coverage. In own recent work, we use data from the IAB Establishment Panel and find wages to be positively related to firm-

\footnotetext{
${ }^{1}$ Moreover, there are number of related studies which use intra-national variations in bargaining structures to analyse the impact of the bargaining structure on the wage level and on the returns to worker attributes. See e.g. Hartog et al. (2002) and Cardoso and Portugal (2003).
} 
profits. However, this appears to be true only for non-covered establishments, since we fail to detect any positive relationship between wages and firm-specific profitability conditions in firms that are subject to a collective wage agreement - irrespective of whether the agreement is industry- or firm-specific (Gürtzgen 2005). However, like any other analysis using such aggregate data, these results are subject to the limitations of establishment- or firm-level data. First, there may be unobserved worker heterogeneity, which is unlikely to be fully captured by establishment level data. Second, aggregate data generally provide a rather crude measure of wages. The IAB Establishment Panel only offers information on the reported wagebill exclusive of fringe-benefits or bonus payments. Whenever rent-sharing takes the form of such supplemental payments, the use of these data will clearly entail an understatement of the true wage-profit relationship.

In this paper, we investigate the relationship between wages and profitability using the IAB Linked Employer-Employee data set (LIAB) which combines data from the Employment Statistics Register and the IAB Establishment Panel. This data set is especially useful for our purposes since it enables us to match individual data with establishment-specific information on value added and collective bargaining coverage. A particular advantage is the exact information on earnings due to the administrative nature of the Employment Statistics Register. In our estimation strategy, we first focus on simple static pooled Ordinary Least Squares (POLS) estimates, without taking into account the endogeneity of rents and unobserved individual as well as plant-specific effects. The OLS estimations serve as a benchmark case and will be modified in various respects. First, we will address the possibility of unobserved individual time invariant factors. Second, we will consider both establishment- and individual-level unobserved heterogeneity by estimating differenced spell-fixed effects models. A final problem concerns the endogeneity of our profitability measure, since wages and profits are simultaneously determined. To address this problem, we will instrument profits by using a differenced GMM-estimator according to Arellano and Bond (1991).

The main results are as follows: In Germany, individual wages are found to be positively related to firm-specific rents. However, this seems to be true only for wage determination in the non-union sector and under firm-specific contracts. In establishments that are covered by an industry-wide wage contract, pooled OLS estimates yield a positive correlation between wages and quasi-rents, but estimates accounting for unobserved individual and establishment heterogeneity point to a coefficient of zero. In examining the impact of collective bargaining coverage on the wage-profit relationship, our findings therefore support the notion that centralised wage bargain- 
ing suppresses any positive responsiveness to local profitability conditions. Differenced GMM estimates accounting for the endogeneity of our profitability measure even point to a negative relationship between wages and firm-specific profitability under centralised contracts. Although this result is difficult to interpret, it leads us at least to conclude that the lower responsiveness of wages to firm-specific conditions under centralised contracts was not simply due to a downward-bias caused by the endogeneity of quasi-rents.

The remainder of the paper is organised as follows: the theoretical and institutional background is presented in Section 2. Section 3 describes the general empirical model, the data set and the main variables used in the subsequent analysis. Section 4 presents the results from the pooled OLS, fixed effects and differenced GMM estimations. Finally, Section 5 provides a discussion and some conclusions.

\section{Is there any scope for firm-level rent-sharing in Germany?}

In the literature, various theoretical explanations have been advanced for a positive relationship between wages and profits (see e.g. Blanchflower et al. 1996, Hildreth and Oswald 1997). First, in a competitive labour market a positive (short-run) wageprofit correlation may result from temporary frictions. With an upward sloping labour supply curve, demand shocks and associated higher profits may lead to a positive co-movement between wages and profits. Second, a positive relationship between wages and profits may be the result of efficiency wage mechanisms, with higher wages feeding into higher profits due to productivity enhancing effects. Such effects may arise, for example, from reductions in turnover and shirking (see e.g. Krueger and Summers 1988). Third, a frequently invoked explanation refers to rent-sharing due to union power. If wages are determined by collective bargaining, wages may be expected to increase with profits, as unions will be able to appropriate part of the industry- or firm-specific rents. It has been extensively argued that the sensitivity of wages to industry- and/or to firm-specific conditions crucially depends on the level of wage bargaining. Based on cross-country comparisons, a number of studies find the magnitude of inter-industry wage differentials to be substantially lower in countries that are characterised by highly centralised and coordinated bargaining institutions (e.g., Holmlund and Zetterberg 1991, Edin and Zetterberg 1992, Kahn 1998). Apparently, a similar result is likely to hold for inter-firm wage differentials. The underlying notion is that firm wage differentials are likely to be small, if, e.g., 
industry-wide wage determination provides no possibility to adjust wages to local conditions at the firm-level.

The German system of wage bargaining is usually characterised as mediumcentralised, with regional and industry-wide collective wage agreements (Flächentarifverträge) being the predominant form of wage determination (Calmfors and Driffill 1988, Soskice 1990, OECD 2004). Such central wage agreements are negotiated between an industry-specific trade union and an employers' association. They are legally binding for all firms being member of the respective employers' association and for all employees who are members of the trade union. Although the negotiated wage applies strictly speaking only to union members, member firms generally extend the wage settlement to non-member employees as well. ${ }^{2}$

Given the predominance of centralised wage bargaining, there appears to be little scope for firm level rent-sharing in Germany. Yet, a closer look at German wage determination offers a more subtle picture. Since the early 1990s, German industrial relations have experienced a clear tendency towards more decentralised forms of wage determination (see e.g. Hassel 1999, Kohaut and Schnabel 2003). This tendency is caused by three major developments. First, firm-specific collective wage agreements have become more frequent. Those agreements are negotiated between an individual firm and industry-specific unions. Second, wage determination without any bargaining coverage is becoming more relevant. In firms not being covered by a collective agreement wage determination may either take the form of individual wage contracts or of plant-specific agreements (Betriebsvereinbarungen) between works councils and the management. ${ }^{3}$ Third, there is a tendency even within centralised wage agreements to allow for more flexibility at the firm-level. In recent years, contractual opting-out clauses or hardship clauses have become a widespread element of central agreements. While opening clauses delegate issues that are usually specified in the central agreement, such as working-time and pay-conditions, to the plant-level, hardship clauses enable firms to be exempted from the centralised agreement if they are close to bankruptcy. In general, the adoption of such clauses requires the approval of the collective bargaining parties (Hassel 1999, Ochel 2005). Moreover, since bargained wages in

\footnotetext{
${ }^{2}$ The reason is that non-unionised employees who would receive a lower wage may be expected to join the union anyway in order to benefit from the higher union wage. Moreover, central wage agreements may also apply to non-member firms and their employees if the agreement is declared to be generally binding by the Federal Ministry of Labour.

${ }^{3}$ According to the German Works Constitution Act, works councils are not allowed to negotiate about issues that are normally dealt with in collective agreements, even in firms that are not parties of a collective agreement. In practice, however, works councils may be expected to play a crucial role in wage determination (see e.g. Hassel 1999, Hübler and Jirjahn 2003).
} 
centralised agreements merely represent a lower bound for wages, there is also sufficient room for upward flexibility. ${ }^{4}$ To sum up, recent decentralisation tendencies in Germany have introduced - at least formally - the possibility to adjust wages to local conditions at the firm level. However, at this point it is worthy to note that the question of whether this potential has really been exploited still remains to be answered empirically. For example, even though contractual opening and hardship clauses have become an important (formal) element of centralised agreements, empirical evidence on the use of such clauses is rather sparse. ${ }^{5}$

\section{Empirical Analysis}

\subsection{Empirical Model and Testable Hypotheses}

In order to quantify the relationship between firm-specific profitability and individual wages, we consider a wage equation taking the following form:

$$
\ln w_{i t}=\mu+\beta_{\pi} \cdot \pi_{j(i, t) t}+\boldsymbol{\gamma} \cdot \mathbf{x}_{i t}^{\prime}+\boldsymbol{\delta} \cdot \mathbf{u}_{i}^{\prime}+\boldsymbol{\eta} \cdot \mathbf{w}_{j(i, t) t}^{\prime}+\boldsymbol{\rho} \cdot \mathbf{q}_{j(i, t)}^{\prime}+\lambda_{t} \cdot D_{t}+\alpha_{i}+\phi_{j(i, t)}+\epsilon_{i t}
$$

There are $i=1, \ldots, N$ individuals, and $N^{*}=\sum T_{i}$ total worker-year observations. $j(i, t)$ refers to the firm which employs individual $i$ at time $t$, with $j=1, \ldots, J$. The dependent variable, $\ln w_{i t}$, is the individual log daily wage. The explanatory variable of main interest is $\pi_{j(i, t) t}$, measuring (time-varying) firm-specific per-capita profitability. $\mathbf{x}_{i t}^{\prime}$ represents a vector of time-varying individual covariates with a coefficient vector $\gamma$, while $\mathbf{u}_{i}^{\prime}$ denotes a vector of individual time-constant characteristics with a coefficient vector $\boldsymbol{\delta}$. Similarly, $\mathbf{w}_{j(i, t) t}^{\prime}$ and $\mathbf{q}_{j(i, t)}^{\prime}$ represent time-varying and time constant $j$-level covariates with coefficient vectors $\eta$ and $\boldsymbol{\rho} . \alpha_{i}$ and $\phi_{j(i, t)}$ denote individual and firm-specific unobserved heterogeneities. Finally, industry dummies are included to capture industry-specific factors, such as the overall level of industry demand and the degree of competition. Time dummies $D_{t}$ are included to capture common macroeconomic shocks, and $\epsilon_{i t}$ is a white-noise error term.

Since the emphasis of our analysis is on the impact of collective bargaining coverage on the sensitivity of wages to firm-specific profitability conditions, the coefficient $\beta_{\pi}$ is specified to depend on the contract-type:

\footnotetext{
${ }^{4}$ Using data from the IAB Establishment Panel, Bellmann et al. (1998) find about 50 per cent of all Western German establishments that are covered by a collective contract to pay wages above the going rate.

${ }^{5}$ One exception is the study by Franz and Pfeiffer (2003), who analyse this issue based on an employer-survey of about 800 German firms. Their results indicate that only 18 per cent of those employers that covered by a collective contract allowing for hardship clauses make use of such provisions.
} 


$$
\beta_{\pi}=\beta_{0}+\beta_{\pi_{-} C E N T} \cdot C E N T_{i t}+\beta_{\pi_{-} F I R M} \cdot F I R M_{i t},
$$

where $C E N T$ is a dummy taking the value of unity if a firm is subject to an industry-wide collective wage contract and FIRM takes on the value of unity if a firm is party to a firm-specific collective wage agreement. Thus, we will interact our profitability measure with collective bargaining coverage. $\beta_{0}+\beta_{\pi_{-} C E N T}$ then measures the responsiveness of wages to firm-specific profits in firms that are covered by a centralised wage contract, whereas $\beta_{0}+\beta_{\pi_{-} F I R M}$ reflects the sensitivity of wages to firm profits in firms that are covered by a firm-specific wage agreement. Finally, the responsiveness of wages to firm profits without any bargaining coverage is measured by $\beta_{0}$.

Bargaining power considerations suggest the sign of $\beta_{\pi_{F I R M}}$ to be positive, i.e. the sensitivity of wages to firm-specific profits is likely to be larger under firm-specific contracts than in non-covered firms. An important argument is that firm-specific contracts in Germany are concluded by industry-specific unions. This distinguishes German firm-specific collective wage agreements from similar wage agreements in other countries, as e.g. in the U.K., where firm-specific unions bargain independently from each other (see e.g. OECD 2004). For this reason, the bargaining power of works councils determining wages in non-covered firms may be expected to be considerably lower than that of an industry-wide union, which determines wages under firm-specific contracts. This prediction is re-enforced by the fact that the wage bargaining process under firm-specific contracts is highly coordinated by an industrywide union, whereas it is completely uncoordinated in non-covered firms. While wage-setting acteurs in non-covered firms have an incentive to cut wages in order to gain a larger share of industry-demand, this competitive mechanism completely disappears with an industry-union (see Gürtzgen 2005). This leads us to expect an industry union to capture a larger share of rents under firm-specific contracts than, say, works-councils in non-covered firms.

The sign of $\beta_{\pi_{-} C E N T}$ cannot be predicted a-priori, since this depends on the fraction of firms making use of flexibility provisions in centralised wage agreements. In particular, we expect $\beta_{\pi_{-} C E N T}$ to be positive, if flexibility provisions are used to adjust wages to local profitability conditions (for the same reason as under firmspecific contracts). Conversely, testing $\beta_{\pi_{C E N T}}=-\beta_{0}$ provides a direct test of a complete invariance of wages against firm-specific conditions. Since our data lack explicit information on the use of flexibility provisions in firms that are subject to a centralised wage agreement, we will interpret our empirical findings as an indirect 
test of whether the use of flexibility provisions in industry-wide wage agreements is a quantitatively important phenomenon in Germany.

Having derived hypotheses about the role of collective bargaining for the wageprofit relationship, it may also be useful to consider the importance of individual characteristics. The differential effects measured by the interaction terms ought to be particularly pronounced among those groups of workers who are likely to be covered by collective contracts. While our data contain information on collective bargaining coverage at the establishment level, they unfortunately lack explicit information on whether an individual worker is covered or not. There are a number of studies that analyse the determinants of individual union membership in Germany (e.g., Beck and Fitzenberger 2004, Goerke and Pannenberg 2004), but empirical evidence on individual collective bargaining coverage is rather scarce. ${ }^{6}$ International empirical evidence suggests individual non-coverage to be particularly relevant among highskilled managerial workers (see e.g. Hartog et al. 2002). As a result, we expect the interaction effects to be stronger for low- and medium-skilled blue-collar workers.

In non-covered establishments, a positive wage-profit correlation may be the result of efficiency wage mechanisms on the one hand and of bargaining power on the other hand. Efficiency wage considerations lead us to expect the wage-profit correlation to be particularly strong among the better educated. The reason is that those workers are more likely to accumulate firm-specific human capital and are less likely to be supervised than low-skilled workers. This raises the relative incentive for employers to pay above market-clearing wages in order to reduce turnover and shirking. Note that the supervision argument should also hold for white-collar as compared to bluecollar workers. The same conclusions can be drawn in case of rent-sharing as the result of individual wage bargaining power, because highly educated workers may be expected to have better outside options and higher bargaining power than low-skilled individuals. Finally, rent-sharing in non-covered establishments may also result from the bargaining power of works councils. Thus, the extent of rent-sharing ought to be larger for those groups of workers whose wages are likely to be affected by workscouncils. Empirical evidence on the presence of works-councils generally suggests that the likelihood of codetermination increases with the share of male as well as skilled workers (see Addison et al. 1997, Hübler and Jirjahn 2003, Zwick 2004). This may be interpreted as a weak hint for wages of those groups being more likely to be influenced by works councils than those of female and low-skilled individuals.

\footnotetext{
${ }^{6}$ Note that individual union membership is not a necessary condition for individual bargaining coverage, since firms often extend the wage contract to non-member employees as well.
} 


\subsection{Data and Variable Description}

The empirical analysis uses the IAB Linked Employer-Employee data set (LIAB) which combines data from the IAB Establishment Panel and the Employment Statistics Register. The IAB Establishment Panel is based on an annual survey of West-German establishments administered since 1993 by the research institute (IAB -Institute of Employment Research) of the Federal Employment Services in Nuremberg. East German establishments entered the panel in 1996. The database is a representative sample of German establishments employing at least one employee who pays social security contributions. The survey data provide numerous information on establishment structure and performance, as e.g. sales, the share of materials in sales and investment expenditures (see e.g. Bellmann et al. 2002). Moreover, the data set contains information on whether an establishment is covered by an industrywide collective wage agreement, a firm-specific wage agreement or by no collective agreement at all.

The worker information comes from the Employment Statistics Register, which is an administrative panel data set of all employees paying social security contributions (see e.g. Bender et al. 2000). The data are based on notifications which employers are obliged to provide for each employee covered by the social security system. Those notifications are required whenever an employment relationship begins or ends. In addition, there is at least one annual compulsory notification for all employees who are employed on the $31^{\text {st }}$ December of each year. The Employment Statistics Register includes individual information on the gross daily wage, gender, age, nationality among others. Due to its administrative nature, this database has the advantage of providing reliable information on daily earnings that are subject to social security contributions. The establishment and worker data sets contain a unique establishment identification number. This allows us to match information on all employees covered by the social security system with the establishments in the IAB Establishment Panel.

The construction of the Linked Employer-Employee data set occurs in two steps: First, we select establishments from the establishment panel data set. From the available waves 1993 to 2001, we use the years 1995 to 2001, since detailed information on bargaining coverage is available only from 1995 on. Since information on a number of variables, as e.g. sales and the share of materials in total sales are gathered retrospectively for the preceding year, we lose information on the last year. Moreover, we restrict our sample to establishments from the mining and manufacturing sector with at least two employees. We focus on these industries, since the introduction of opening and hardship clauses here has been particularly relevant in central collective 
wage agreements. These sectors therefore provide an particularly interesting case for testing the empirical relevance of the use of such clauses. As we will apply dynamic panel data methods, only establishments with consistent information on the variables of interest (described below) and at least three consecutive time series observations are included in our sample. This results in a sample of 843 establishments with 3,498 observations, yielding an unbalanced panel containing establishment-observations with, on average, 4.15 years of data. ${ }^{7}$

In the second step, the establishment data are merged with notifications for all employees who are employed by the selected establishments on June $30^{\text {th }}$ of each year. From the worker data we drop observations for apprentices, part-time workers and homeworkers. To avoid modeling human capital formation and retirement decisions, we exclude individuals younger than 19 and older than 55. Moreover, since we consider only full-time workers, we eliminate those whose wage is less than twice the lower social security contribution limit. In order to be able to conduct firstdifferencing, we consider only those individuals for whom at least two consecutive time series observations are available. The final sample comprises 333,044 individuals in 821 establishments, yielding an unbalanced panel containing 3,361 establishment years and 1,305,703 individual observations with, on average, 3.92 years of data for each worker. ${ }^{8}$

The individual data include information on the gross daily wage, age, gender, nationality, employment status (blue-/white-collar), education and on the date of entry into the establishment. The latter is used to approximate tenure by subtracting the entry date from the ending date of the employer's notification which is available from the worker data. Note, however, that this proxy does not account for potential employment interruptions which might have occurred during this time span.

Educational status includes six categories: No degree, vocational training degree, high school degree (Abitur), high school degree and vocational training, technical college degree and university degree. ${ }^{9}$ The dependent variable in the subsequent analysis will be the real gross daily wage. Since there is an upper contribution limit to the social security system, gross daily wages are top-coded. In our sample, top-coding

\footnotetext{
${ }^{7}$ Originally, the sample includes 2,897 establishments with consistent information on all the variables of interest. 12 observations were dropped due to suspected errors in the rent variable. These observations featured per-capita values of rents of above 1 million DM. This results in a sample of 2,891 establishments with a total of 6,404 observations. Only 843 of those feature at least three consecutive time-series observations.

${ }^{8}$ Note that the exclusion of certain individual groups entails a loss of 22 establishments.

${ }^{9}$ Missing and inconsistent data on education are corrected according to the imputation procedure described in Fitzenberger et al. (2005). This procedure relies, roughly speaking, on the assumption that individuals cannot lose their educational degrees.
} 
affects 7.7 per cent of all observations. To address this problem, we construct 36 cells based on education, gender and year. For each cell, a tobit regression is estimated with log daily wages as the dependent variable and individual and establishment covariates as well as industry dummies as explanatory variables (see Table 1 below). As described in Gartner (2005), right-censored observations are replaced by wages randomly drawn from a truncated normal distribution whose moments are constructed by the predicted values from the Tobit regressions and whose (lower) truncation point is given by the contribution limit to the social security system. After this imputation procedure, nominal wages are deflated by the Consumer Price Index of the Federal Statistical Office Germany normalised to 1 in 2000.

Turning to the establishment variables, the main variables used in the subsequent empirical analysis are defined as follows. Following the majority of the rent-sharing literature (see e.g. see Abowd and Lemieux 1993, van Reenen 1996), establishment profitability, $\pi$, is measured by per-capita quasi-rents. We choose quasi-rents - defined as value-added minus the opportunity cost of labour - for two reasons. First, from a theoretical perspective quasi-rents may be interpreted as representing the 'pie' to be divided between the bargaining parties. Second, from an econometric perspective, the use of quasi-rents instead of profits enables us to circumvent the endogeneity problem induced by the accounting relationship between wages and profits. In particular, we construct per capita quasi-rents as the difference between annual sales, material costs and the alternative annual wagebill divided by firm size, so that

$$
\pi=\frac{S A L E S-M A T E R I A L C O S T-\bar{w} \cdot S I Z E}{S I Z E} .
$$

Firm size $(S I Z E)$ is calculated as the number of employees reported for the month June averaged over the present and preceding year. The alternative wagebill, $\bar{w}$. $S I Z E$, is defined as the annual wagebill which each firm would incur if it had to pay the average industrial wage. Thus, we approximate $\bar{w}$ by the weighted average of industry-specific wages for blue- and white-collar workers with the weights being the establishment-specific shares of those worker groups in the total work force. ${ }^{10}$ The fractions of blue- and white-collar workers are taken from the establishment data because the Employment Statistics Register provides the individual employment status only for full-time workers. All monetary values are expressed as real values by deflating them with a sector-specific producer price index normalised to 1 in 2000 .

\footnotetext{
${ }^{10}$ We convert sectoral hourly industrial wages of blue collar workers into monthly wages by multiplying them with firm-specific average working time. Since information on average sectoral wages of white-collar workers is available only on a monthly basis, we are not able to adjust those wages for firm-specific average working time. Monthly values are converted into annual values by multiplying them with the factor 12 .
} 
Industry-specific price indices and wages are obtained from the Federal Statistical Office Germany and are matched to the establishment-data on the basis of a twodigit sector classification (WZ 93).

Note that the profitability measure does not account for capital costs, because our data lack explicit information on such costs. However, we attempt to control for differences in capital intensities. As we do not directly observe the capital stock, we need to construct a proxy. We measure firm capital by using the perpetual inventory method starting from the capital value in the first observation year and using the information on expansion investment in the following years. The initial capital value is proxied by dividing investment expenditures in each firm's first observation year by a pre-period growth rate of investment, $g$, and a depreciation rate of capital, $\delta .{ }^{11}$ Capital-stocks in subsequent periods are calculated by adding real expansion investment expenditures. ${ }^{12}$ To obtain real values, nominal investment expenditures are deflated by the producer price index of investment goods of the Federal Statistical Office Germany. The capital-labour ratio, $K / L$, is constructed by dividing the resulting capital proxy by firm size. Finally, further establishment variables include the existence of a works council as well as information on industry-specific and firm-specific collective bargaining coverage.

Table 1 presents summary statistics for the variables used in the subsequent analysis. The first two columns report statistics averaged over individuals, whereas the last two columns present statistics that are averaged over establishments. Note that both statistics partly differ substantially from each other due to the underlying distribution of establishment size. Becauser larger establishments pay on average higher wages and are more profitable in terms of per-capita quasi-rents, the underlying sample means are lower on the establishment level. Moreover, there are also considerable differences with respect to collective bargaining coverage. In particular, it can be seen that large establishments are much more likely to be covered by an industry-wide agreement, whereas small establishments are more likely to belong to the non-union sector. As a result, the overwhelming majority of individuals ( 88 per cent) are employed by an establishment that adopts an industry-wide agreement. The fraction of individuals in establishments that are subject to a firm-specific agreement amounts to 8 per cent.

\footnotetext{
${ }^{11}$ This involves the assumption that investment expenditures on capital have grown at a constant average rate, $g$, so that the capital stock in the base year is $K_{1}=I_{0}+(1-\delta) I_{-1}+(1-\delta)^{2} I_{-2}+$ $\ldots=I_{1} \sum_{s=0}^{\infty}\left[\frac{1-\delta}{1+g}\right]^{s}=I_{1} /(\delta+g)$. In particular, to calculate $K_{1}$, we set $\delta=0.1$ and $g=0.05$ (see Hempell 2002).

${ }^{12}$ More specifically, $K_{t}=K_{t-1}(1-\delta)+I_{t-1}=K_{t-1}+E I_{t-1}$, where $K_{t}$ is the capital stock at the beginning of period $t$, i.e. at the end of period $t-1$, and $E I_{t}$ are expansion investment expenditures in period $t$.
} 
Table 1: Summary statistics

\begin{tabular}{llrrrr}
\hline \hline Variable & Definition & \multicolumn{1}{c}{ Mean } & Std.-Dev. & \multicolumn{1}{c}{ Mean } & Std.-Dev. \\
\cline { 2 - 6 } & & \multicolumn{2}{c}{ Individual level } & Establishm. level \\
\hline Individual characteristics & & & & \\
$\ln w$ & Real log daily wage in DM & 5.21 & 0.31 & 4.91 & 0.32 \\
FEMALE & Female worker & 0.19 & 0.39 & 0.24 & 0.22 \\
AGE & Age in years & 39.05 & 9.03 & 38.92 & 3.42 \\
TENURE & Tenure in months & 135.62 & 86.15 & 93.95 & 48.73 \\
FOREIGN & Foreign worker & 0.10 & 0.31 & 0.06 & 0.10 \\
WHITECOLL & White-collar worker & 0.37 & 0.48 & 0.32 & 0.22 \\
VOCATIO & Vocational Degree & 0.67 & 0.47 & 0.75 & 0.20 \\
HIGHSCHOOL & Highschool Degree & $4.7 e^{-03}$ & 0.07 & $3.8 e^{-03}$ & 0.02 \\
VOC-HIGH & Voc. and Highschool Degree & 0.03 & 0.16 & 0.02 & 0.05 \\
TECHN-UNI & Technical Univ. Degree & 0.06 & 0.24 & 0.05 & 0.08 \\
UNI & University Degree & 0.06 & 0.24 & 0.04 & 0.07 \\
\hline Establishment & characteristics & & & & \\
$\pi$ & Per-capita quasi-rents & 1.06 & 0.80 & 0.67 & 0.80 \\
SIZE & Firm size & $6,680.88$ & $12,430.58$ & 550.89 & $2,075.87$ \\
CENT & Centralised agreement & 0.88 & 0.31 & 0.62 & 0.44 \\
FIRM & Firm-specific agreement & 0.08 & 0.25 & 0.12 & 0.26 \\
WCOUNCIL & Works council & 0.97 & 0.15 & 0.64 & 0.47 \\
K/L & Capital-labour ratio & 1.94 & 4.01 & 2.25 & 12.3 \\
EAST & Eastern Germany & 0.15 & 0.35 & 0.43 & 0.49 \\
\hline Individuals & & 333,044 & & & \\
Establishments & & & & & 821 \\
\hline \hline
\end{tabular}

Source: LIAB 1995-2001. 821 establishments, 333,044 individuals, 1,305,703 observations.

Note: Per-capita quasi rents and the capital-labour ratio are measured in 100,000 DM.

$1 €$ corresponds to $1.95583 \mathrm{DM}$. 
Finally, only 4 per cent of all individuals are subject to no agreement at all, even though the fraction of non-covered establishments amounts to about 26 per cent. Breaking down the sample into those individual observations covered by an industrywide agreement, a firm-specific agreement and into those without any bargaining coverage reveals that wages are highest under industry-wide agreements and lowest without any bargaining coverage (see Table A1 in the Appendix). The variability in wages is higher for individuals without any bargaining coverage with a coefficient of variation of 0.08 as compared to 0.06 and 0.07 for individuals who work in a firm that is covered by a collective contract. Moreover, workers covered by firm-specific agreements are, on average, employed by more profitable and capital-intensive firms, followed by those working in firms that are subject to an industry-wide agreement.

\section{Results}

\subsection{Estimation Strategy}

We first focus on a simple static pooled Ordinary Least Squares (POLS) specification of eq. (2), in which neither $\alpha_{i}$ nor $\phi_{j(i, t)}$ are controlled for. The POLS estimations serve as a benchmark case and will be modified in various respects: First, we control for individual unobserved heterogeneity to assess the extent to which unobservably more productive workers work in more profitable plants. Second, we address the possibility of unobserved plant-specific time invariant factors. Finally, we address the endogeneity of per-capita rents by using dynamic panel data methods.

\subsection{Pooled OLS-Results}

Table 2 reports the results from the POLS estimations of the impact of quasi-rents per worker on individual log wages. Quasi-rents are specified in levels rather than logs, since the use of logs would have required discarding all observations with negative quasi-rents.

In the first simplest model, which includes quasi-rents as the only explanatory variable, the estimate of quasi-rents per employee on the individual wage is 0.110 . Adding individual characteristics increases the explanatory power of the model considerably (by a factor of more than six) and reduces the coefficient to 0.061, suggesting that almost 50 per cent of the correlation between rents and wages is due to systematic sorting of workers across firms (Model (2)). In particular, high-qualified workers appear to be associated with more profitable firms. The effects of rents on wages are further reduced when including other firm characteristics, such as firm size, bargain- 
Table 2: Pooled OLS regression results

\begin{tabular}{|c|c|c|c|c|c|c|}
\hline Model & (1) & (2) & (3) & (4) & $(5)$ & (6) \\
\hline$\pi$ & $\begin{array}{l}0.110^{* * *} \\
(0.016)\end{array}$ & $\begin{array}{l}0.061^{* * *} \\
(0.007)\end{array}$ & $\begin{array}{l}0.038^{* * *} \\
(0.008)\end{array}$ & $\begin{array}{l}0.025^{* * *} \\
(0.005)\end{array}$ & $\begin{array}{l}0.033^{* * *} \\
(0.005)\end{array}$ & $\begin{array}{l}0.100^{* * *} \\
(0.013)\end{array}$ \\
\hline$\pi_{-} \mathrm{CENT}$ & & & & & & $\begin{array}{l}-0.076^{* * *} \\
(0.014)\end{array}$ \\
\hline$\pi \_$FIRM & & & & & & $\begin{array}{l}-0.010 \\
(0.016)\end{array}$ \\
\hline SIZE/1000 & & & $\begin{array}{l}0.018^{* * *} \\
(0.003)\end{array}$ & $\begin{array}{l}0.014^{* * *} \\
(0.003)\end{array}$ & $\begin{array}{l}0.008^{* * *} \\
(0.003)\end{array}$ & $\begin{array}{l}0.008^{* * *} \\
(0.003)\end{array}$ \\
\hline $\mathrm{SIZE}^{2} / 1000$ & & & $\begin{array}{l}-3.10 e^{-07 * * *} \\
\left(5.24 e^{-08}\right)\end{array}$ & $\begin{array}{l}-2.40 e^{-07 * * *} \\
\left(5.48 e^{-08}\right)\end{array}$ & $\begin{array}{l}-1.17 e^{-07 * *} \\
\left(4.95 e^{-08}\right)\end{array}$ & $\begin{array}{c}-1.11 e^{-07 * *} \\
\left(4.83 e^{-08}\right)\end{array}$ \\
\hline CENT & & & $\begin{array}{l}0.128^{* * *} \\
(0.031)\end{array}$ & $\begin{array}{l}0.077^{* * *} \\
(0.028)\end{array}$ & $\begin{array}{l}0.078^{* * *} \\
(0.027)\end{array}$ & $\begin{array}{l}0.139^{* * *} \\
(0.031)\end{array}$ \\
\hline FIRM & & & $\begin{array}{l}0.098^{* * *} \\
(0.034)\end{array}$ & $\begin{array}{l}0.063^{* *} \\
(0.029)\end{array}$ & $\begin{array}{l}0.074^{* * *} \\
(0.026)\end{array}$ & $\begin{array}{l}0.063^{* *} \\
(0.027)\end{array}$ \\
\hline WCOUNCIL & & & $\begin{array}{l}0.153^{* * *} \\
(0.024)\end{array}$ & $\begin{array}{l}0.146^{* * *} \\
(0.019)\end{array}$ & $\begin{array}{l}0.117^{* * *} \\
(0.020)\end{array}$ & $\begin{array}{l}0.113^{* * *} \\
(0.019)\end{array}$ \\
\hline$(\mathrm{K} / \mathrm{L})$ & & & $\begin{array}{l}0.001 \\
(0.002)\end{array}$ & $\begin{array}{l}0.002^{* * *} \\
(0.008)\end{array}$ & $\begin{array}{l}0.002^{* * *} \\
(0.008)\end{array}$ & $\begin{array}{l}0.002^{* * *} \\
(0.007)\end{array}$ \\
\hline EAST & & & & $\begin{array}{l}-0.243^{* * *} \\
(0.017)\end{array}$ & $\begin{array}{l}-0.242^{* * *} \\
(0.014)\end{array}$ & $\begin{array}{l}-0.236^{* * *} \\
(0.014)\end{array}$ \\
\hline $\begin{array}{l}\text { Individual } \\
\text { controls }\end{array}$ & No & Yes & Yes & Yes & Yes & Yes \\
\hline Ind.-/Time & No & No & No & No & Yes & Yes \\
\hline Adj. $R^{2}$ & 0.09 & 0.564 & 0.624 & 0.674 & 0.695 & 0.699 \\
\hline Establishments & 821 & 821 & 821 & 821 & 821 & 821 \\
\hline Individuals & 333,044 & 333,044 & 333,044 & 333,044 & 333,044 & 333,044 \\
\hline Observations & $1,305,703$ & $1,305,703$ & $1,305,703$ & $1,305,703$ & $1,305,703$ & $1,305,703$ \\
\hline
\end{tabular}

Source: LIAB 1995-2001.

Note: The dependent variable is the individual log daily wage. Standard errors are in parentheses, and are adjusted for clustering at the establishment level. Individual control variables include gender, nationality, education (6 categories), a dummy for white-collar workers, tenure, tenure squared, age, age squared. All specifications include 16 two-digit industy-dummies and 5 time dummies. *** Significant at $1 \%$-level, ${ }^{* *}$ Significant at $5 \%$-level. 
ing coverage, the existence of a works council and the capital-labour ratio (Model (3)). Apart from the capital-labour ratio $K / L$, all control variables enter the regression with their expected sign and are all significant at the 1 per cent level. In line with earlier evidence, firm size is found to have a significant positive effect on individual wages. ${ }^{13}$ In the literature, the positive firm size effect is usually explained by differences in profitability conditions, capital equipment, worker quality and monitoring costs among others (see e.g. Oi and Idson 1999). As our specifications explicitly control for worker quality, the capital-labour ratio and quasi-rents, the firm size variable may be interpreted as capturing some part of unobserved worker quality and technology differences.

The effects of quasi-rents on wages are further reduced after adding an eastwest dummy, which is in accordance with less favourable economic conditions in East German establishments (Model (4)). Moreover, controlling for establishment location leads to a larger and more precise estimate of the capital-labour ratio on wages, indicating systematic differences in capital intensity across regions. Note that the coefficients on CENT and FIRM drop significantly in Model (4), which reflects the much lower extent of collective bargaining coverage among East German employers.

Given the predominance of industry-level wage bargaining, it might be conceivable that the positive effect of quasi-rents on wages was primarily due to rent-sharing on the industry level. For this reason, we investigate whether the positive correlation is robust to the inclusion of 16 two-digit industry dummies (Model (5)). Controlling for industry affiliation increases the coefficient on rents even somewhat, suggesting that rent-sharing in Germany mainly takes place within industries.

Finally, our main interest concerns the question whether the rent-coefficient varies systematically with collective bargaining coverage. To investigate this issue, Model (6) includes interactions between collective bargaining coverage and rents. The results indicate that the extent to which wages react to firm-specific profitability conditions is significantly lower in firms that are covered by a centralised wage agreement. However, the null hypothesis of $\beta_{0}=-\beta_{\pi_{-} C E N T}$ can be rejected at conventional levels, suggesting that the overall impact of rents on wages is still positive. In firms that are covered by a firm-specific contract, wages do not appear to be less sensitive to rents as the coefficient on the interaction term is found to be insignificant.

\footnotetext{
${ }^{13}$ For German evidence on employer size effects see e.g. Schmidt and Zimmermann (1991) and Gerlach and Hübler (1998).
} 


\subsection{Individual fixed effects}

Even though we have controlled for observable individual characteristics, it might be conceivable that the positive effect of quasi-rents on individual wages was due to sorting of unobservably more productive workers into more profitable establishments. To assess the extent to which sorting affects our estimates, we next control for unobserved individual heterogeneity. First-differencing of eq. (2) sweeps-out the individual effect $\alpha_{i}$ :

$$
\Delta \ln w_{i t}=\beta_{\pi} \cdot \Delta \pi_{j(i, t) t}+\boldsymbol{\gamma} \cdot \Delta \mathbf{x}_{i t}^{\prime}+\boldsymbol{\eta} \cdot \Delta \mathbf{w}_{j(i, t) t}^{\prime}+\boldsymbol{\rho} \cdot \Delta \mathbf{q}_{j(i, t)}^{\prime}+\lambda_{t} \cdot \Delta D_{t}+\Delta \phi_{j(i, t)}+\Delta \epsilon_{i t}
$$

Note that first-differencing also eliminates individual time-constant characteristics $\mathbf{u}_{i}$, so that the coefficient vector $\boldsymbol{\delta}$ cannot be identified. ${ }^{14}$ Model (1) and (2) in Table 3 report the individual first-differenced regressions results. The specifications include the full set of time-varying covariates from Model (5) and (6) in Table 2. While Model (1) contains no interaction terms, Model (2) allows the coefficients to vary with collective bargaining coverage. Note that the number of observations drops from 1,305,703 to 971,056 since we lose one observation for 331,441 individuals and two observations for those $(1,603)$ whose time series exhibits a gap.

In Model (1), quasi-rents enter the equation with a positive sign, but the coefficient is not statistically significant. Interestingly, in Model (2), where the effect is allowed to vary with collective bargaining coverage, the coefficients are more precisely estimated. While the coefficient on quasi-rents is significantly positive for non-covered establishments, the effect is found to be significantly lower under centralised wage agreements. In contrast to the POLS results, a Wald-test fails to reject the null $\beta_{0}=-\beta_{\pi_{-} C E N T}$ (with a $p$-value of 0.53 ), indicating that the overall effect of rents on wages is even zero under centralised contracts. For firm-specific contracts, the interaction term is found to be negative, but not significantly different from zero. Overall, the estimated effects of quasi-rents on wages are much lower than the POLS estimates. This finding is indicative of some systematic sorting of unobservably more productive workers into more profitable firms. Given that the POLS upward-bias is found to be relatively larger under centralised agreements, sorting appears to play a major role for firms that are covered by a centralised wage contract. One possible explanation might be that centralised wage contracts lead to a more compressed wage structure across skill groups which causes firms to upgrade the quality of their workforce. This might lead to higher unobserved worker productivity in such firms and therefore to (relatively larger) upward-biased estimates in the simple pooled OLS-specification.

As regards the remaining establishment variables, in both specifications firm size,

\footnotetext{
${ }^{14}$ In our specification, individual time-constant covariates are gender and nationality.
} 
Table 3: Individual and spell first-differenced regression results

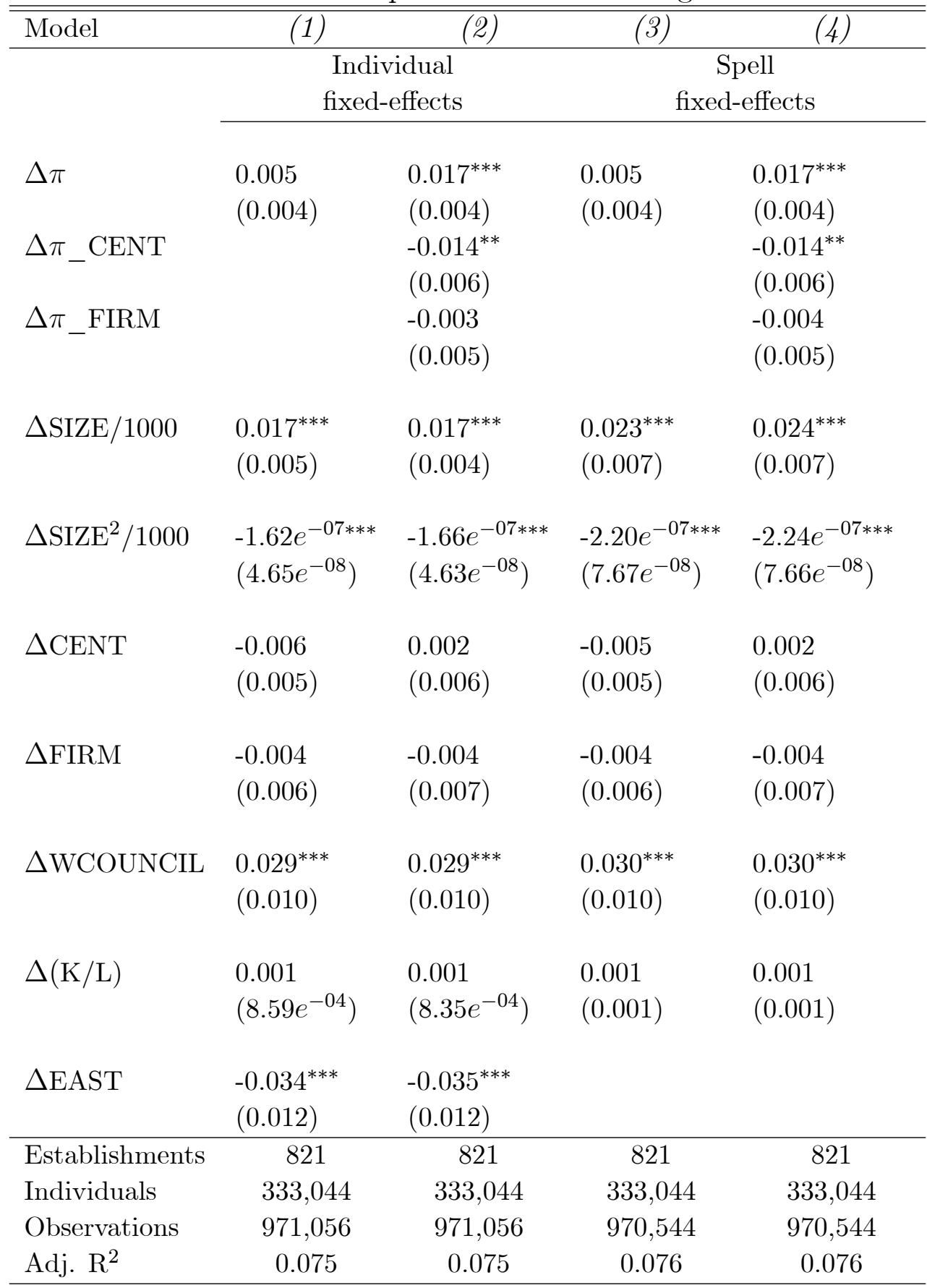

Source: LIAB 1995-2001.

Note: The dependent variable is the first-differenced individual log daily wage.

Standard errors are in parentheses and are adjusted for clustering at the establishment level. Individual control variables include education (6 categories), a white-collar-dummy, tenure, tenure squared, age, age squared.

All specifications include 16 two-digit industy-dummies and 5 time dummies.

${ }^{* * *}$ Significant at $1 \%$-level, ${ }^{* *}$ Significant at $5 \%$-level. 
the works council and the east-west dummy are found to be significantly different from zero and enter the equations with their expected sign. Presumably due to their low variability over time, the collective bargaining dummies and the capital-labour ratio are imprecisely estimated and are for the most part incorrectly signed.

\subsection{Spell fixed effects}

Apart from unobserved individual heterogeneity, a further source of bias may be the presence of unobserved establishment effects that are correlated with our profitability measure. In our context, the presence of unobserved establishment heterogeneity may result from neglected capital costs in the quasi-rent measure as well as from differences in technological conditions ${ }^{15}$ that are not captured by our control variables. In this case, consistent estimates of the parameters of interest may be obtained by taking differences within each individual-establishment combination (see Abowd et al. 1999). Andrews et al. (2004) label these combinations as individual-establishment-'spells'. Defining $\theta_{s}=\alpha_{i}+\phi_{j(i, t)}$ in eq. (2) as the unobserved spell-level effect for spell $s$, first-differencing of eq. (2) yields:

$$
\Delta \ln w_{i t}=\beta_{\pi} \cdot \Delta \pi_{j(i, t) t}+\boldsymbol{\gamma} \cdot \Delta \mathbf{x}_{i t}^{\prime}+\boldsymbol{\eta} \cdot \Delta \mathbf{w}_{j(i, t) t}^{\prime}+\boldsymbol{\rho} \cdot \Delta \mathbf{q}_{j(i, t)}^{\prime}+\lambda_{t} \cdot \Delta D_{t}+\Delta \theta_{s}+\Delta \epsilon_{i t}
$$

Thus, first-differencing of eq. (2) removes $\theta_{s}$, as long as differencing occurs within each spell. In addition to eliminating individual time-constant characteristics, firstdifferencing sweeps out time-constant establishment variables $\mathbf{q}_{j(i, t)}^{\prime}$, so that the coefficient vector $\boldsymbol{\rho}$ cannot be identified either. ${ }^{16}$ The extent to which the spell fixed effects estimates differ from the individual fixed effects results depends on the fraction of individuals who move between establishments within our sample. In the extreme case of no turnover between sample establishments, spell- and individual fixed effects would yield the same results, and $\alpha_{i}$ and $\phi_{j(i, t)}$ could not be separately identified. Table 4 reports the distribution of the number of spells. The figures show that the majority of individuals (99.84 per cent) do not move between establishments, only 526 out of 333,044 workers (corresponding to 0.16 per cent) move from one sample establishment to another. ${ }^{17}$

\footnotetext{
${ }^{15}$ With respect to differences in technologies, firm-specific fixed effects capture e.g. production processes that provide firms with higher rents and which may require compensating wage differentials (e.g. processes involving dangerous work). Such differences might lead to a positive wage-rent correlation which would not be due to rent-sharing (see e.g. Margolis and Salvanes 2001).

${ }^{16}$ Time-constant establishment variables are the east-west and the industry dummies.

${ }^{17}$ The low proportion of movers is due to the fact that the establishment data are a sample of establishments, so that the probability of observing a worker moving from one sample establishment to another is very small.
} 
Table 4: Movers and non-movers

\begin{tabular}{lrrr}
\hline \hline & Individuals & $\begin{array}{l}\text { Spell per } \\
\text { Individual }\end{array}$ & Spells \\
\hline Non-movers & 332,518 & 1 & 332,518 \\
Movers & 524 & 2 & 1,048 \\
Movers & 2 & 3 & 6 \\
\hline All & 333,044 & & 333,572 \\
\hline \hline
\end{tabular}

Source: LIAB 1995-2001.

Columns (3) and (4) in Table 3 contain the results from the spell first-differenced regressions. Since differencing requires at least two consecutive time periods within each spell, we need to exclude 448 spells with only one observation per spell. The remaining number of spells is 333,124 . Since one observation per spell is lost in first differencing within each spell and 1,587 spells exhibit a gap in their time series, the number of observations drops to 970,544. As expected, due to the tiny proportion of individuals who change their employer, the estimates do not substantially differ from the individual first-differenced estimates. As in specification (2), quasi-rents are found to exert a significantly lower impact on wages in establishments that are subject to a centralised wage contract (Model (4)). Similar to Model (2), a Wald-test fails to reject the null of a zero-rent coefficient (with a $p$-value of 0.46). Although the point-estimate of the interaction term for firm-specific contracts is negative, it is not significantly different from zero. Overall, our findings therefore suggest that centralised wage bargaining suppresses any wage dispersion due to diverging profitability conditions, whereas firm-specific contracts and no collective bargaining coverage allow wages to respond to firm-specific profits. Note that with spell level fixed effects, unobserved heterogeneity captures both individual and establishment effects. An interesting issue would be to recover estimates of $\alpha_{i}$ and $\phi_{j(i, t)}$ and to examine whether unobservably better individuals work in establishments that are characterised by (unobservable) high-wage policies. However, owing to the low proportion of movers in our sample we do not pursue this issue further, since for a large number of firms such an identification would have to rely on very little information to obtain estimates of the establishment effects.

\subsection{The wage-profit correlation across various worker groups}

To investigate whether the relationship between wages and quasi-rents varies systematically across various worker groups, we additionally ran regressions separately by gender, for blue-collar and white-collar workers and for different skill-types. Table 5 reports the results for males and females and for blue- and white-collar workers. 
Columns (1) and (2) hold the results of the gender-specific regressions. For the female sample, we obtain a coefficient in non-covered establishments which amounts to about 50 per cent of the corresponding point estimate for males. Even though the difference is not statistically significant and may partly be attributed to gender differences in the skill-composition ${ }^{18}$, the lower point estimate for females may be interpreted as weak evidence for lower rent-extraction of women. Note that this is consistent with former evidence obtained by Arai (2001), Black and Strahan (2001), Nekby (2003) and Martins (2004) among others. As to the interaction terms, the signs of the rent-coefficients exhibit the same pattern as in the pooled regressions. For each group, the null of $\beta_{0}=-\beta_{\pi_{-} C E N T}$ cannot be rejected (with $p$-values of 0.38 for males and 0.80 for females). Thus, industry-wide wage agreements appear to reduce inter-firm wage differentials both for men and women to a similar extent, indicating that the extent of inter-firm wage compression under centralised contracts is stable across both groups. Moreover, similar to the pooled regressions, the interaction terms for firm-specific contracts are found to be not significantly different from zero, and this result holds for either group.

Columns (3) and (4) report the results for blue- and white-collar workers. First of all, the point estimates in non-covered establishments do not significantly differ from each other, suggesting a similar extent of rent-sharing across occupations. Note that this finding does not support the efficiency wage hypothesis due to diverging supervision intensities, because such mechanisms led us to expect the relationship between wages and quasi-rents to be larger among white-collar workers. As to the interaction terms, centralised contracts appear to reduce rent-sharing particularly among blue-collar workers. Among white-collar workers, the interaction effect is less negative and not statistically different from zero. While the null of zero rentsharing under centralised contracts cannot be rejected for blue-collar workers (with a $p$-value of 0.77 ), this hypothesis is to be rejected at conventional levels for whitecollar workers. Although these results must be interpreted with caution because of the smaller sample size for white-collar workers, they support our hypothesis that inter-firm wage differentials of blue-collar workers are more likely to be compressed by centralised contracts than those of white-collar workers.

Table 6 reports separate regression results for different skill-types. As before, in non-covered establishments quasi-rents are found to exert a positive impact on wages. Note, however, that due to the smaller sample size the estimates for low- and high-skilled workers are much more imprecise than those for medium-skilled workers.

\footnotetext{
${ }^{18}$ For example, the share of workers without any vocational degree is 28.9 per cent among female workers and 15.3 per cent among male workers.
} 
Table 5: Rent-sharing across various worker groups

\begin{tabular}{|c|c|c|c|c|}
\hline Model & (1) & (2) & (3) & (4) \\
\hline \multirow{3}{*}{$\Delta \pi$} & Female & Male & Blue-collar & White-collar \\
\hline & $0.010^{* *}$ & $0.019^{* * *}$ & $0.018^{* * *}$ & $0.018^{* *}$ \\
\hline & $(0.005)$ & $(0.004)$ & $(0.003)$ & $(0.008)$ \\
\hline \multirow[t]{2}{*}{$\Delta \pi \_$CENT } & -0.011 & $-0.015^{* *}$ & $-0.016^{* * *}$ & -0.010 \\
\hline & $(0.006)$ & $(0.006)$ & $(0.006)$ & $(0.008)$ \\
\hline \multirow[t]{2}{*}{$\Delta \pi \_$FIRM } & 0.001 & -0.006 & -0.009 & -0.004 \\
\hline & $(0.006)$ & $(0.005)$ & $(0.004)$ & $(0.008)$ \\
\hline \multirow[t]{2}{*}{$\Delta \mathrm{SIZE} / 1000$} & 0.018 & $0.024^{* * *}$ & $0.016^{* *}$ & $0.034^{* * *}$ \\
\hline & $(0.010)$ & $(0.007)$ & $(0.007)$ & $(0.001)$ \\
\hline \multirow[t]{2}{*}{$\Delta \mathrm{SIZE}^{2} / 1000$} & $-1.73 e^{-07}$ & $-2.27 e^{-07 * * *}$ & $-1.77 e^{-07 * *}$ & $-2.91 e^{-07 * *}$ \\
\hline & $\left(9.55 e^{-08}\right)$ & $\left(7.56 e^{-08}\right)$ & $\left(7.64 e^{-08}\right)$ & $\left(1.27 e^{-07}\right)$ \\
\hline \multirow[t]{2}{*}{$\triangle \mathrm{CENT}$} & 0.001 & 0.004 & 0.002 & 0.008 \\
\hline & $(0.004)$ & $(0.007)$ & $(0.006)$ & $(0.007)$ \\
\hline \multirow[t]{2}{*}{$\Delta \mathrm{FIRM}$} & -0.002 & -0.003 & -0.003 & 0.010 \\
\hline & $(0.005)$ & $(0.008)$ & $(0.007)$ & $(0.008)$ \\
\hline \multirow[t]{2}{*}{$\triangle \mathrm{WCOUNCIL}$} & -0.014 & $0.036^{* * *}$ & $0.027^{* * *}$ & 0.022 \\
\hline & $(0.011)$ & $(0.008)$ & $(0.007)$ & $(0.014)$ \\
\hline \multirow[t]{2}{*}{$\Delta(\mathrm{K} / \mathrm{L})$} & $7.51 e^{-04}$ & 0.001 & $9.80 e^{-04}$ & 0.001 \\
\hline & $(0.002)$ & $\left(9.16 e^{-04}\right)$ & $(0.001)$ & $(0.001)$ \\
\hline Establishments & 760 & 807 & 804 & 760 \\
\hline Observations & 167,176 & 803,368 & 614,520 & 356,024 \\
\hline Adj. $R^{2}$ & 0.111 & 0.075 & 0.076 & 0.136 \\
\hline
\end{tabular}

Source: LIAB 1995-2001.

Note: The dependent variable is the first-differenced individual log daily wage. All variables are spell first-differenced. Standard errors are in parentheses and are adjusted for clustering at the establishment level.

For individual control variables see Tables 2 and 3 .

All specifications include 5 time dummies.

${ }^{* * *}$ Significant at $1 \%$-level, ${ }^{* *}$ Significant at $5 \%$-level. 
Table 6: Rent-sharing across skill-types

\begin{tabular}{|c|c|c|c|}
\hline Model & (1) & (2) & (3) \\
\hline \multirow{3}{*}{$\Delta \pi$} & Low-skilled & Medium-skilled & High-skilled \\
\hline & 0.009 & $0.017^{* * *}$ & 0.018 \\
\hline & $(0.006)$ & $(0.003)$ & $(0.015)$ \\
\hline \multirow[t]{2}{*}{$\Delta \pi \_$CENT } & -0.011 & $-0.013^{* * *}$ & -0.011 \\
\hline & $(0.008)$ & $(0.005)$ & $(0.016)$ \\
\hline \multirow[t]{2}{*}{$\Delta \pi \_$FIRM } & -0.003 & -0.005 & $-2.26 e^{-04}$ \\
\hline & $(0.008)$ & $(0.004)$ & $(0.016)$ \\
\hline \multirow[t]{2}{*}{$\Delta$ SIZE/1000 } & $0.019^{* *}$ & $0.018^{* * *}$ & $0.048^{* *}$ \\
\hline & $(0.009)$ & $(0.007)$ & $(0.021)$ \\
\hline \multirow[t]{2}{*}{$\Delta \mathrm{SIZE}^{2} / 1000$} & $-2.22 e^{-07 * *}$ & $-1.82 e^{-07 * *}$ & $-4.12 e^{-07 * *}$ \\
\hline & $\left(9.35 e^{-08}\right)$ & $\left(7.17 e^{-08}\right)$ & $\left(2.00 e^{-07}\right)$ \\
\hline \multirow[t]{2}{*}{$\triangle \mathrm{CENT}$} & -0.008 & 0.006 & 0.001 \\
\hline & $(0.008)$ & $(0.004)$ & $(0.022)$ \\
\hline \multirow[t]{2}{*}{$\Delta \mathrm{FIRM}$} & -0.018 & 0.002 & 0.028 \\
\hline & $(0.010)$ & $(0.005)$ & $(0.019)$ \\
\hline \multirow[t]{2}{*}{$\triangle$ WCOUNCIL } & 0.001 & $0.027^{* * *}$ & 0.002 \\
\hline & $(0.022)$ & $(0.007)$ & $(0.019)$ \\
\hline \multirow[t]{2}{*}{$\Delta(\mathrm{K} / \mathrm{L})$} & 0.005 & 0.001 & $-1.82 e^{-05}$ \\
\hline & $(0.006)$ & $\left(9.63 e^{-04}\right)$ & $(0.003)$ \\
\hline Establishments & 588 & 815 & 575 \\
\hline Observations & 171,198 & 688,801 & 110,545 \\
\hline Adj. $R^{2}$ & 0.060 & 0.091 & 0.265 \\
\hline
\end{tabular}

Source: LIAB 1995-2001.

Note: See Table 5 .

Low-skilled workers are those without any vocational degree, medium-skilled are those holding a vocational degree, high-skilled workers hold a technical university degree or a university degree.

${ }^{* * *}$ Significant at $1 \%$-level, ${ }^{* *}$ Significant at $5 \%$-level. 
As hypothesized earlier, efficiency wage mechanisms and individual bargaining power considerations lead us to expect the relationship between wages and quasi-rents to be particularly pronounced among the better educated. Although the estimates in noncovered establishments do not significantly differ from each other, the higher point estimates for medium- and high-skilled workers suggest the profit-effect on wages to be larger among higher skill groups, which appears to support our hypotheses. As regards bargaining coverage, the signs of the rent-coefficients exhibit the same pattern as in the pooled regressions. As before, the interaction effects for firm-specific contracts are found to be very small and not significantly different from zero, and this is true for each skill group. Industry-wide wage agreements seem to reduce interfirm wage differentials for all skill groups, even though the interaction effect is found to be significant only for medium-skilled workers. The overall effect of quasi-rents on wages under centralised contracts is largest for high-skilled workers (with a point estimate of about 0.007). Even though the estimated effect is very imprecise, this result may be interpreted as weak evidence for a more pronounced inter-firm wage dispersion among high-skilled workers as compared to their low- and medium-skilled counterparts. This finding is supportive of the notion that inter-firm wage differentials of high-skilled workers are less prone to be compressed by centralised wage agreements than those of low- and medium-skilled workers, since the latter are much more likely to be covered by collective contracts.

Given that 70 per cent of all non-covered establishments in our sample are located in East Germany, a further concern might be that the pattern of responses to firm-specific rents is driven by systematic regional differences in wage formation. To investigate this issue, we ran separate regressions for East and West-German establishments. The regressions yielded coefficients of $0.008,-0.004$ and 0.008 for West Germany and 0.015, -0.018 and -0.013 for East Germany (for no-coverage, centralised contracts and firm-specific contracts, respectively). Even though the Eastern sample is much smaller than the Western sample (125,089 versus 845,455 observations), the coefficients for Eastern establishments are all significantly different from zero, whereas the estimates for West Germany are all found to be insignificant. This exercise leads us to conclude that centralised contracts seem to suppress inter-firm wage differentials in either region, while the profit-sensitivity of wages in non-covered establishments is much more pronounced in East Germany.

\subsection{Endogeneity bias}

Even though the use of quasi-rents instead of profits mitigates the endogeneity problem induced by the negative accounting relationship between wages and profits, our 
profitability measure might still be endogenous. A first source of bias is a standard simultaneity bias which occurs if wages, output and quasi-rents are jointly determined. In general, the direction of bias can go either way and largely depends on the underlying relationship between output and employment. If there are, for example, decreasing returns in the use of labour, high wages will cause quasi-rents per worker to increase, and this will induce an upward-bias in the estimates of the rent-coefficient (see Abowd and Lemieux 1993). Second, because alternative wages and individual wages are likely to be positively correlated, there will always be some source of downward bias. The potential endogeneity of the profitability measure raises the question as to whether the pattern of previous results holds if the endogeneity of quasi-rents is accounted for. For example, an important concern might be that the invariance of wages against firm-specific conditions under centralised contracts was simply caused by a downward-bias due the endogeneity of quasi-rents. To address this problem, we apply the differenced Generalized Methods of Moments (GMM) estimator as proposed by Arellano and Bond (1991). By exploiting available moment conditions around the error term, this estimator instruments endogenous variables with suitable lagged values. In particular, first differencing of eq. (1) causes any first-differenced endogenous variable $\Delta x_{i t-1}$ to become correlated with the error term $\Delta u_{i t}$. In the absence of second-order correlation in the error term, $x_{i t-2}$ and earlier lags will provide suitable instruments, since they will be uncorrelated with $\Delta u_{i t}$. Note that in our specifications, not only quasi-rents, but also their interactions with collective bargaining coverage are likely to be endogenous variables.

Apart from instrumenting endogenous variables by their lagged values in $t-2$ and earlier, the differenced GMM estimator provides an appropriate treatment of predetermined variables which are assumed to be uncorrelated with $u_{i t}$ and $u_{i t+1}$, but are correlated with $u_{i t-1}$. As first differencing causes such variables to become correlated with the error term $\Delta u_{i t}$, they are instrumented by lagged values in $t-1$ and earlier. In particular, we allow firm size and the capital-labour ratio to be predetermined in order to capture potential feedback effects from wages in period $t$ on those covariates in subsequent periods. To test the validity of the moment conditions, we present the Sargan/Hansen test of overidentifying restrictions. This test statistic calculates the correlation of the error terms with the instrument matrix and has an asymptotic $\chi^{2}$ distribution under the null that the moment conditions are valid. Moreover, we report diagnostics for second-order serial correlation of the error terms (testing the null of no second-order serial correlation).

Table 7 gives the results of the differenced GMM estimates. ${ }^{19}$ The estimates

\footnotetext{
${ }^{19}$ Because of the low mobility of individuals between sample plants, we confine the presentation
} 
Table 7: First-differenced GMM results

\begin{tabular}{|c|c|c|c|}
\hline Model & $\begin{array}{l}\operatorname{GMM}(\mathrm{t}-2) \\
\end{array}$ & $\begin{array}{l}2 \\
\operatorname{GMM}(\mathrm{t}-3)\end{array}$ & $\begin{array}{l}3 \\
\operatorname{GMM}(\mathrm{t}-4)\end{array}$ \\
\hline$\Delta \pi$ & $\begin{array}{l}0.023^{* * *} \\
(0.002)\end{array}$ & $\begin{array}{l}0.033^{* * *} \\
(0.005)\end{array}$ & $\begin{array}{l}0.054^{* * *} \\
(0.005)\end{array}$ \\
\hline$\Delta \pi * \mathrm{CENT}$ & $\begin{array}{l}-0.054^{* * *} \\
(0.002)\end{array}$ & $\begin{array}{l}-0.070^{* * *} \\
(0.005)\end{array}$ & $\begin{array}{l}-0.102^{* * *} \\
(0.006)\end{array}$ \\
\hline$\Delta \pi * \mathrm{FIRM}$ & $\begin{array}{l}0.019^{* * *} \\
(0.003)\end{array}$ & $\begin{array}{l}0.016^{* * *} \\
(0.005)\end{array}$ & $\begin{array}{l}0.008 \\
(0.006)\end{array}$ \\
\hline$\Delta \mathrm{SIZE} / 1000$ & $\begin{array}{l}0.043^{* * *} \\
(0.001)\end{array}$ & $\begin{array}{l}0.045^{* * *} \\
(0.001)\end{array}$ & $\begin{array}{l}0.043^{* * *} \\
(0.001)\end{array}$ \\
\hline$\Delta \mathrm{SIZE}^{2} / 1000$ & $\begin{array}{l}-4.74 e^{-07 * * *} \\
\left(9.97 e^{-09}\right)\end{array}$ & $\begin{array}{l}-5.02 e^{-07 * * *} \\
\left(1.02 e^{-08}\right)\end{array}$ & $\begin{array}{l}-4.94 e^{-07 * * *} \\
\left(1.03 e^{-08}\right)\end{array}$ \\
\hline$\triangle \mathrm{CENT}$ & $\begin{array}{l}0.025^{* * *} \\
(0.001)\end{array}$ & $\begin{array}{l}0.035^{* * *} \\
(0.002)\end{array}$ & $\begin{array}{l}0.052^{* * *} \\
(0.003)\end{array}$ \\
\hline$\Delta \mathrm{FIRM}$ & $\begin{array}{l}-0.026^{* * *} \\
(0.001)\end{array}$ & $\begin{array}{l}-0.026^{* * *} \\
(0.002)\end{array}$ & $\begin{array}{l}-0.026^{* * *} \\
(0.003)\end{array}$ \\
\hline$\triangle \mathrm{WCOUNCIL}$ & $\begin{array}{l}0.027^{* * *} \\
\left(8.36 e^{-04}\right)\end{array}$ & $\begin{array}{l}0.027^{* * *} \\
\left(8.71 e^{-04}\right)\end{array}$ & $\begin{array}{l}0.027^{* * *} \\
\left(8.90 e^{-04}\right)\end{array}$ \\
\hline$\Delta(\mathrm{K} / \mathrm{L})$ & $\begin{array}{l}0.001^{* * *} \\
\left(2.46 e^{-04}\right)\end{array}$ & $\begin{array}{l}0.001^{* * *} \\
\left(2.64 e^{-04}\right)\end{array}$ & $\begin{array}{l}0.003^{* * *} \\
\left(3.20 e^{-04}\right)\end{array}$ \\
\hline$\Delta(\mathrm{EAST})$ & $\begin{array}{l}-.067^{* * *} \\
(0.003)\end{array}$ & $\begin{array}{l}-.073^{* * *} \\
(0.003)\end{array}$ & $\begin{array}{l}-0.080^{* * *} \\
(0.003)\end{array}$ \\
\hline Sargan- $\chi^{2}(k)$ & $16,631.48(75)$ & $15,614.65(57)$ & $13,450,85(48)$ \\
\hline ( $p$-value $)$ & 0.00 & 0.00 & 0.00 \\
\hline $\operatorname{AR}(2) \quad(p$-value $)$ & 0.00 & 0.00 & 0.00 \\
\hline Individuals & 333,044 & 333,044 & 333,044 \\
\hline Observations & 971,056 & 971,056 & 971,056 \\
\hline
\end{tabular}

*** Significant at $1 \%$-level. ${ }^{* *}$ Significant at $5 \%$-level.

Source: LIAB 1995-2001.

Note: The dependent variable is the first-differenced individual log daily wage

Heteroscedasticity robust standard errors are in parentheses. For remaining covariates see Table 3. Results are reported for the one-step GMM-estimator. 
reported in Column (1) use lagged values of quasi-rents and their interactions with collective bargaining coverage in $t-2$ and earlier as instruments. Turning to the main variables of interest, the signs of the rent-coefficients exhibit a similar pattern as the individual and spell fixed-effects estimates in Table 3. While the rent-coefficient is significantly positive for non-covered establishments, wages appear to be less sensitive to rents if establishments are covered by a centralised wage agreement. Compared to the fixed-effects estimates, the point estimate for non-covered establishments turns out to be somewhat larger, suggesting that the endogeneity of quasi-rents led to a slight downward bias in the fixed effects esimates. Note that the overall effect under centralised agreements appears to be even negative, since a Wald-test rejects the null of $\beta_{0}=-\beta_{\pi_{-} C E N T}$ at conventional levels. Interestingly, the interaction term for firm-specific contracts is estimated to be significantly positive, once the endogeneity of quasi-rents is accounted for. Note that this is supportive of our hypothesis that firm-specific contracts ought enable strong sector unions to skim off a larger share of rents than wage-setting acteurs in non-covered establishments. Overall, these results indicate that the fixed effects estimates neglecting the endogeneity of quasi-rents led to a downward biased estimate of the rent-coefficient under firm-specific contracts and in non-covered establishments and to an upward-biased coefficient under centralised contracts. Note, however, that the overall performance of the GMM estimates turns out to be somewhat disappointing, since the specification obviously fails to pass the test of overidentifying restrictions and the $\mathrm{AR}(2)$-test.

Given that lagged values in $t-2$ do not appear to be valid instruments for quasirents and their interactions with collective bargaining coverage, we ran an additional specification using lagged values since $t-3$ and earlier as instruments (reported in Column (2)), and a further model using lagged values since $t-4$ and earlier (reported in Column (3)). The estimates yield larger rent-effects on wages in non-covered establishments and under centralised contracts (in absolute value), but reduce the interaction coefficients under firm-specific contracts, even though the overall effects are increased. However, the Sargan statistics again fail to confirm the validity of the moment conditions in either specification. In sum, this leads us to judge the general performance of the GMM estimates to be rather unsatisfactory. These objections notwithstanding, the estimates do at least appear to preserve the pattern of results obtained by the fixed-effects estimates and point to a remarkably stable pattern of the responsiveness of wages to profits. Most importantly, they suggest that the lower responsiveness of wages to firm-specific conditions under centralised contracts was not simply caused by a downward-bias due to the endogeneity of quasi-rents. to the individual first-differenced estimates. 
Even though the result of a negative rent-effect under centralised contracts is difficult to interpret, the estimates lead us to conclude that a positive effect of rents on wages prevails only in non-covered establishments and under firm-specific contract. This partly corroborates our results from recent work on the basis of establishment level data, where we failed to detect any positive relationship between wages and firm-specific quasi-rents under centralised contracts. However, in finding a positive amount of rent-sharing under firm-specific contracts, the present results stand in contrast to our findings from the establishment-level estimations, which pointed to a complete insensitivity of wages to firm-specific conditions under firm-specific contracts (Gürtzgen 2005). Note that this difference may partly be attributed to the more precise and encompassing information on wages in the LIAB data, where wages are measured inclusive of fringe-benefits or bonus payments.

Given the coefficients of 0.017 to 0.054 and mean quasi-rents per employee of 0.70 , the elasticity of individual wages with respect to quasi-rents is of the magnitude 0.01 to 0.04 in non-covered plants. In establishments subject to a firm-contract, elasticities range from 0.02 to 0.08 (with coefficients ranging between 0.013 and 0.062 and a mean value of 1.21). Is is interesting to note that these figures are remarkably similar to other estimates obtained with linked employer-employee data: Margolis and Salvanes (2001) report elasticities between 0.002 and 0.03 for France and corresponding values of 0.006 between 0.01 for Norway. The relative magnitude of these elasticities largely reflect differences in bargaining institutions in both countries, with firm-level bargaining prevailing in France and a two-ladder system with sector-level bargaining and subsequent firm-level negotiations being predominant in Norway. A similar system prevails in Sweden, which is consistent with comparable estimates obtained by Arai (2003), who reports an elasticity of 0.01. Finally, Martins (2004) reports elasticities ranging between -0.031 and 0.078 for Portugal, which is characterised by a mixed bargaining system of sectoral, single-firm and multi-firm contracts.

\section{Summary and Conclusions}

The aim of this paper is twofold: First, we address the question of whether German wages respond to firm-specific profitability conditions and second, we are interested in whether the sensitivity of wages to firm-specific rents depends on collective bargaining coverage. Theoretical considerations lead us to expect the sensitivity of wages to firmspecific rents to be larger under firm-specific contracts than in non-covered firms. The same is likely to hold for industry-wide agreements, provided the bargaining 
parties make use of flexibility provisions, which recently have become a widespread element of central wage agreements. Since direct information on the use of flexibility provisions in firms subject to an industry-wide wage agreement is unavailable, we take our empirical findings as indirect evidence of whether the use of such provisions is a quantitatively important phenomenon in Germany.

Using linked employer-employee data from the mining and manufacturing sector, our empirical analysis offers a remarkably consistent picture: Individual wages are found to be positively related to firm-specific quasi-rents, but this seems to be confined to the non-union sector and to establishments subject to firm-specific contracts. Industry-wide wage contracts, however, appear to suppress any positive responsiveness of wages to local profitability conditions. While pooled OLS estimates yield a positive correlation between wages and quasi-rents under centralised contracts, estimates accounting for unobserved individual and establishment heterogeneity point to a coefficient of zero. Moreover, the pooled OLS upward-bias is found to be relatively larger under centralised contracts. This finding is indicative of the presence of unobserved factors that are positively related with profits and impact positively upon wages, and which are particularly relevant under centralised contracts. One such factor may be that a compressed wage structure under centralised wage contracts causes firms to upgrade the quality of their workforce. This might lead to higher unobserved worker productivity in such firms and therefore to (relatively larger) upward-biased estimates in the simple pooled OLS-specification. Differenced GMM estimates accounting for the endogeneity of our profitability measure even point to a negative relationship between wages and firm-specific profitability under centralised contracts. Although this finding is difficult to interpret, it leads us to conclude that the lower responsiveness of wages to firm-specific conditions under centralised contracts does not simply result from a downward-bias due to the endogeneity of quasi-rents. Moreover, we find wages under firm-specific contracts to react stronger to firm-specific profitability than in non-covered establishments, once the endogeneity of quasi-rents is accounted for. This finding is supportive of our hypothesis that firm-specific contracts ought enable strong sector unions to skim off a larger share of rents than, for example, works councils in non-covered establishments.

In examining the impact of collective bargaining coverage on the wage-profit relationship, our findings therefore suggest that centralised wage bargaining suppresses any positive responsiveness to firm-specific profitability conditions and that the use of flexibility provisions in central wage agreements appears to be empirically negligible. Even though firms may pay wages above the going rate and may make use of optingout clauses, this potential for positive adjustments to local profitability conditions 
seems to be largely unused. To reconcile this result with the fact that a considerable fraction of firms covered by a collective contract pay wages above the going rate, we conclude from our findings that such wages do not arise from more favourable profitability conditions, but rather reflect observable and unobservable differences in worker productivity.

Consistent with our hypotheses that the extent of inter-firm wage compression under centralised contracts ought to be particularly pronounced among those workers who are likely to be covered by collective contracts, we find the wages of lowand medium-skilled blue-collar workers to be most insensitive to firm profits. In noncovered establishments, we find skilled and male workers to benefit to a larger extent from their employers' ability-to-pay than unskilled and female workers which is in accordance with efficiency wage mechanisms as well as bargaining power considerations. 


\section{References}

[1] Abowd, J.M. and T. Lemieux (1993), The effects of product market competition on collective bargaining agreements: The case of foreign competition in Canada, The Quarterly Journal of Economics 108, 983-1014.

[2] Abowd, J.M., Kramarz, F. and D.N. Margolis (1999), High-wage workers and high-wage firms, Econometrica 67, 251-333.

[3] Addison, J., Schnabel, C. and J. Wagner (1997), On the determinants of mandatory works councils in Germany, Industrial Relations 36, 419-445.

[4] Andrews, M., Schank, T. and R. Upward (2004), Practical estimation methods for linked employer-employee data, IAB-Discussion Paper No. 3/2004, Nürnberg.

[5] Arai, M. (2003), Wages, profits and capital-intensity: evidence from matched worker-firm data, Journal of Labor Economics 21, 593-618.

[6] Arellano, M. and S.R. Bond (1991), Some tests of the specification for panel data: Monte Carlo evidence and an application to employment equations, Review of Economic Studies 58, 277-297.

[7] Beck, M. and B. Fitzenberger (2004), Changes in union membership over time: A panel analysis for West Germany, Labour 18, 329-362.

[8] Bellmann, L., Kohaut, S. and C. Schnabel (1998), Ausmaß und Determinanten der übertariflichen Entlohnung, IW-Trends 25/2, 5-14.

[9] Bellmann, L., Kohaut, S. and M. Lahner (2002), Das IAB-Betriebspanel Ansatz und Analysepotenziale, in: Kleinhenz, G. (ed.), IAB-Kompendium Arbeitsmarkt- und Berufsforschung, Beiträge zur Arbeitsmarkt- und Berufsforschung 250, 13-20. Nürnberg.

[10] Bender, S. , A. Haas and C. Klose (2000), IAB-Employment Subsample 19751995. Opportunities for analysis provided by the anonymised subsample, IZA Discussion Paper No. 117. Bonn.

[11] Black, S.E. and P.E. Strahan (2001), The division of spoils: rent-sharing and discrimination in a regulated industry, American Economic Review 91, 814-831.

[12] Blanchflower, D.G., Oswald, A.J. and P. Sanfey (1996), Wages, profits, and rent-sharing, Quarterly Journal of Economics 111, 227-251. 
[13] Calmfors, L. and J. Driffill (1988), Centralization of wage bargaining, Economic Policy 6, 12-61.

[14] Cardoso, A. R. and P. Portugal (2003), Bargained wages, wage drift and the design of the wage-setting system, IZA Discussion Paper No. 914, Bonn. Forthcoming under revised title in Journal of Labor Economics.

[15] Christofides, L. and A. Oswald (1992), Real wage determination and rent-sharing in collective bargaining agreements, Quarterly Journal of Economics 107, 9851002 .

[16] Dickens W.T and L.F. Katz (1987), Inter-industry wage differences and industry characteristics, in: K. Lang and J. Leonard (eds.), Unemployment and the structure of labor markets, 48-89. London: Basil Blackwell.

[17] Dobbelaere, S. (2004), Ownership, firm-size and rent-sharing in Bulgaria, Labour Economics 11, 165-189.

[18] Edin, P.A. and J. Zetterberg (1992), Interindustry wage differentials: evidnece from Sweden and a comparison with the United States, American Economic Review 82, 1341-1349.

[19] Fitzenberger, B., Osikominu, A. and R. Völter (2005), Imputation rules to improve the education variable in the IAB Employment Subsample, ZEWDiscussion Paper 05-10. Mannheim.

[20] Franz, W. and F. Pfeiffer (2003), Zur ökonomischen Rationalität von Lohnrigiditäten aus der Sicht von Unternehmen, Jahrbücher für Nationalökonomie und Statistik 223, 23-57.

[21] Gartner, H. (2005): The imputation of wages above the contribution limit with the German IAB employment sample. FDZ Methodenreport Nr. 02/2005, Nürnberg.

[22] Gerlach, K. and O. Hübler (1998), Firm size and wages in Germany - trends and impact of mobility, Empirica 25, 245-261.

[23] Goerke, L. and M. Pannenberg (2004), Norm-based trade union membership: Evidence for Germany, German Economic Review 5, 481-504.

[24] Gürtzgen, N. (2005), Rent-Sharing: Does the bargaining regime make a difference? Theory and empirical evidence, ZEW-Discussion Paper 05-15. 
[25] Hartog, J., Leuven, E. and C. Teulings (2002), Wages and the bargaining regime in a corporatist setting: the Netherlands, European Journal of Political Economy $18,317-331$.

[26] Hartog, J. Pereira, P.T. and J.A.C. Vieira (2002), Bargaining regimes and wages in Portugal, Portuguese Economic Journal 1, 237-268.

[27] Hassel, A. (1999), The erosion of the German system of Industrial Relations, British Journal of Industrial Relations 37, 483-506.

[28] Hempell, T. (2002), What's spurious? What's real? Measuring the productivity impacts of ICT at the firm level, ZEW Discussion Paper 02-42. Mannheim. Forthcoming in Empirical Economics.

[29] Hildreth, A. and A.J. Oswald (1997), Rent-sharing and wages: evidence from company and establishment panels, Journal of Labor Economics 15, 318-337.

[30] Holmlund, B. and J. Zetterberg. (1991), Insider effects in wage determination: evidence from five countries, European Economic Review 35, 1009-1034.

[31] Hübler, O. and A. König (1998), Produktmarkteinflüsse, Renten und Löhne: Eine semiparametrische Untersuchung, in: Gerlach, K. (ed.): Ökonomische Analysen betrieblicher Strukturen und Entwicklungen: das Hannoveraner Firmenpanel, 119-143. Frankfurt.

[32] Hübler, O. and U. Jirjahn (2003), Works councils and collective bargaining in Germany: The impact on productivity and wages, Scottish Journal of Political Economy 51, 471-492.

[33] Kahn, L.M. (1998), Collective bargaining and the interindustry wage structure: International evidence, Economica 65, 507-534.

[34] Katz, L.F. and L.H. Summers (1989), Industry rents: Evidence and implications, Brookings Papers on Economic Activity (Microeconomics), The Brookings Institution, 209-275.

[35] Klodt, T. (2000), Produktmärkte, Rent-Sharing und Lohnhöhe. Frankfurt a.M.

[36] Kohaut, S. and C. Schnabel (2003), Zur Erosion des Fächentarifvertrags: Ausmaß, Einflussfaktoren und Gegenmaßnahmen, Industrielle Beziehungen 10, 193219 .

[37] Kramarz, F. (2003), Wages and international trade, CEPR Discussion Paper No. 3936. London. 
[38] Krueger, A.B. and L.H. Summers (1988), Efficiency wages and the inter-industry wage structure, Econometrica 56, 259-293.

[39] Margolis, D.N. and K.G. Salvanes (2001), Do firms really share rents with their workers?, IZA Discussion Paper 330. Bonn.

[40] Martins, P.S. (2004), Rent sharing before and after the wage bill, IZA-Discussion Paper 1376. Bonn.

[41] Nekby, L. (2003), Gender differences in rent-sharing and its implications for the gender wage gap, Economics Letters 81, 403-410.

[42] Ochel, W. (2005), Decentralizing wage bargaining in Germany - a way to increase employment?, Labour 19, 91-121.

[43] OECD (2004), Employment Outlook, Paris.

[44] Oi, W.Y. and T.L. Idson (1999), Firm size and wages, in: Ashenfelter, O. and D. Card, Handbook of Labor Economics. Vol. 3, Amsterdam.

[45] van Reenen, J. (1996), The creation and capture of rents: wages and innovation in a panel of U.K. companies, Quarterly Journal of Economics 111, 195-226.

[46] Schmidt, C.M. and K.F. Zimmermann (1991), Work characteristics, firm size and wages, Review of Economics and Statistics 73, 705-710.

[47] Slichter, S.H. (1950), Notes on the structure on wages, Review of Economics and Statistics 32, 80-91.

[48] Soskice, D. (1990), Wage determination: The changing role of institutions in advanced industrialized countries, Oxford Review of Economic Policy 6, 36-61.

[49] Zwick, T. (2004), Employee participation and productivity, Labour Economics 11, 715-740. 


\section{A Appendix}

\section{A.1 Summary Statistics by Bargaining Coverage:}

\begin{tabular}{|c|c|c|c|c|c|c|}
\hline \multirow[t]{2}{*}{ Variable } & Mean & Std.-Dev. & Mean & Std.-Dev. & Mean & Std.-Dev. \\
\hline & \multicolumn{2}{|c|}{ Centralised contract } & \multicolumn{2}{|c|}{ Firm level contract } & \multicolumn{2}{|c|}{ No coverage } \\
\hline $\ln w$ & 5.25 & 0.30 & 5.18 & 0.35 & 4.93 & 0.40 \\
\hline FEMALE & 0.17 & 0.38 & 0.18 & 0.39 & 0.26 & 0.44 \\
\hline AGE & 39.10 & 8.75 & 39.35 & 8.67 & 39.16 & 8.59 \\
\hline TENURE & 146.31 & 85.95 & 128.89 & 84.67 & 94.21 & 71.74 \\
\hline FOREIGN & 0.11 & 0.31 & 0.06 & 0.23 & 0.06 & 0.24 \\
\hline WHITECOLL & 0.36 & 0.48 & 0.41 & 0.49 & 0.32 & 0.47 \\
\hline VOCATIO & 0.67 & 0.47 & 0.70 & 0.46 & 0.70 & 0.46 \\
\hline HIGHSCHOOL & 0.01 & 0.07 & 0.01 & 0.06 & 0.01 & 0.06 \\
\hline VOC-HIGH & 0.03 & 0.17 & 0.03 & 0.18 & 0.03 & 0.16 \\
\hline TECHN-UNI & 0.06 & 0.23 & 0.06 & 0.24 & 0.06 & 0.24 \\
\hline UNI & 0.06 & 0.23 & 0.05 & 0.23 & 0.05 & 0.21 \\
\hline$\pi$ & 1.09 & 0.87 & 1.21 & 0.96 & 0.70 & 0.80 \\
\hline SIZE & $8,493.50$ & $14,149.44$ & $1,855.77$ & $1,841.42$ & 640.56 & 768.29 \\
\hline WCOUNCIL & 0.98 & 0.14 & 0.97 & 0.16 & 0.72 & 0.45 \\
\hline $\mathrm{K} / \mathrm{L}$ & 1.75 & 2.19 & 4.00 & 11.36 & 2.20 & 4.86 \\
\hline EAST & 0.11 & 0.31 & 0.25 & 0.44 & 0.48 & 0.50 \\
\hline Individuals & \multicolumn{2}{|c|}{299,584} & \multicolumn{2}{|c|}{39,943} & \multicolumn{2}{|c|}{22,672} \\
\hline Establishments & \multicolumn{2}{|c|}{582} & \multicolumn{2}{|c|}{185} & \multicolumn{2}{|c|}{310} \\
\hline Observations & \multicolumn{2}{|c|}{$1,152,078$} & \multicolumn{2}{|c|}{105,640} & \multicolumn{2}{|c|}{47,985} \\
\hline
\end{tabular}

Table A1: Summary statistics by bargaining coverage

Source: LIAB 1995-2001.

Note: Per-capita quasi rents and the capital-labour ratio are measured in 100,000 DM.

$1 €$ corresponds to $1.95583 \mathrm{DM}$. 